\title{
First Molecular Identification of Taenia hydatigena in Wild Ungulates in Poland
}

\author{
Katarzyna Justyna Filip (D), ${ }^{1}$ Anna Maria Pyziel, ${ }^{2}$ Witold Jeżewski, ${ }^{1}$ Anna Weronika Myczka, ${ }^{1}$ \\ Aleksander Wiaczesław Demiaszkiewicz, ${ }^{1}$ and Zdzisław Laskowski ${ }^{1}$ \\ ${ }^{1}$ W. Stefanski Institute of Parasitology PAS, Twarda 51/55, 00-818 Warsaw, Poland \\ ${ }^{2}$ Department of Food Hygiene and Public Health Protection, Faculty of Veterinary Medicine, Warsaw University of Life Sciences-SGGW, \\ Nowoursynowska 166, 02-787 Warsaw, Poland
}

\begin{abstract}
The article examines the presence of metacestodes on the liver capsule in two wild boars and on the liver capsule and mediastinum in moose. Cysticerci were identified as Taenia hydatigena metacestodes by morphological features_-size and shape of rostellar hooks and molecular analysis of the partial sequences of cytochrome c oxidase subunit 1 gene. Molecular analysis revealed similarities between the metacestodes isolated from the wild mammals in the present study to T. hydatigena in European wolves. It is possible that infection of moose and wild boar with T. hydatigena metacestode is related to the growth in the wolf population in Europe.
\end{abstract}

Keywords: Taenia hydatigena, Cysticercosis, Moose, Wild boar, Wolf

\section{INTRODUCTION}

Taenia hydatigena is a cosmopolitan tapeworm from domestic and wild canids (Bowman 2009), which can be transmitted to a wide variety of intermediate hosts, including domestic goats, sheep, swine and certain wild ungulates (Bowman 2009; Nguyen et al. 2016). Immediately after migrating through the liver of the intermediate host, the larvae or metacestode of T. hydatigena, commonly known as Cysticercus tenuicollis, typically encyst on the omentum, mesentery and the serosal surface of the liver; however, they can also be found in the lungs, heart, uterus

Electronic supplementary material: The online version of this article (https://doi. org/10.1007/s10393-019-01392-9) contains supplementary material, which is available to authorized users.

Published online: January 23, 2019

Correspondence to: Katarzyna Justyna Filip, e-mail: katarzyna.filip@twarda.pan.pl or kidneys (Gomez-Puerta et al. 2015). Subsequent migration of the larvae can result in traumatic hepatitis, resulting in the death of the host animal (Rostami et al. 2013). Cysticercosis by T. hydatigena results in serious economic losses in livestock production due to condemnation of livers or whole carcass at slaughter, which makes it a matter of veterinary importance (Scala et al. 2015).

In Europe, an important reservoir is maintained in the environment for T. hydatigena by wolves and dogs, which act as definitive hosts, and wild ungulates, which act as intermediate hosts (Gori et al. 2015; Otranto et al. 2015; Lesniak et al. 2017). Taenia hydatigena metacestodes were found in $12.3 \%$ of game cervids in Slovakia (Letkova et al. 2008), 22\% of examined wild ruminants in Belarussian Polesie (Shimalov and Shimalov 2003) and 20\% of wild boars from Saarema in Western Estonia (Järvis et al. 2007). 
In Poland, little epidemiological data regarding the occurrence of T. hydatigena is available and all reports refer exclusively to the infection of intermediate hosts. In the 1960s, cysticercosis was reported in all species of Polish cervidae (Dróżdż 1966). Since then, T. hydatigena metacestode has been found in a single wild boar, and a number of roe deer and moose from central Poland (Gadomska 1981; Tropiło and Kiszczak 1995; Filip and Demiaszkiewicz 2016), as well as a few pigs from the northwestern part of the country (Kędra et al. 2001).

The aim of this study is to provide a morphological and molecular description of T. hydatigena metacestodes identified in wild mammals in Poland.

Twenty wild boars from Strzalowo Forest District $\left(53^{\circ} 45^{\prime} 57.03^{\prime \prime} \mathrm{N}, 21^{\circ} 25^{\prime} 17.79^{\prime \prime} \mathrm{E}\right)$, hunted during 2014 , were necropsied. A single specimen of metacestode of $T$. hydatigena was found on the liver capsule in two of the boars.

In 2016 and 2017, six moose killed in car accidents in Kampinos National Park and 3 moose in Polesie National Park were necropsied. Two T. hydatigena metacestodes were found on the liver capsule and mediastinum of a twoyear-old female moose from Dąbrówka Forest District $\left(52^{\circ} 21^{\prime} 03^{\prime \prime} \mathrm{N} 20^{\circ} 36^{\prime} 05^{\prime \prime} \mathrm{E}\right)$, Kampinos National Park.

To perform morphological analysis, the intact cysticerci and rostellar hooks of metacestodes were measured. To localize the crowns, the cysticerci with all introverted scoleces were mounted in Faure's fluid, without staining. The crowns were extracted from the cysticerci and temporarily mounted for photography and study. For morphological identification, the rostellar hooks were liberated from the crowns using an aqueous solution of $1 \%$ pepsin and $0.4 \% \mathrm{HCl}$ and then mounted in Faure's fluid. Only hooks aligned well in the horizontal plane were used for morphometric analysis and photography. The rostellar hooks were examined according to Haukisalmi et al. (2011), using an Olympus BX50 light microscope with a Cell D digital image analysis system.

The DNA was isolated using the DNA Mikro Kit (Syngen) according to the manufacturer's protocol. The primers Thg452F (5'-TGCATTTAGCTGGTGCGTCAAGTA $\left.-3^{\prime}\right)$ and Thg1326R (5'-ACAAACACGCCGGGGTAACC-3') were used to partially amplify the mitochondrial cytochrome $\mathrm{c}$ oxidase subunit 1 gene ( $\operatorname{cox} 1)$. PCRs were conducted in a $50 \mu \mathrm{l}$ reaction mixture containing $2.0 \mu \mathrm{l}$ of DNA template, $0.2 \mu \mathrm{l}$ (1.0U) of HiFiTaq Polymerase (Novazym), $1 \mu \mathrm{l}$ of dNTPs mix $(10 \mathrm{mM}), 1.0 \mu \mathrm{l}$ of each primer $(20 \mathrm{mM})$ and $5 \mu \mathrm{l}$ of $10 \times$ Polymerase buffer $(\mathrm{pH}$
8.6, $25 \mathrm{mM} \mathrm{MgCl} 2)$ and $40.8 \mu \mathrm{l}$ of deionized water. In the negative control, nuclease-free water was added to the PCR mix instead of the tested DNA.

DNA amplification was performed using the DNA Engine T100 Thermal Cycler (Bio-Rad) using the following programs: The initial denaturation was performed at $95^{\circ} \mathrm{C}$ for one minute, followed by 35 cycles of denaturation at $95^{\circ} \mathrm{C}$ for $20 \mathrm{~s}$, annealing at $56^{\circ} \mathrm{C}$ for $20 \mathrm{~s}$ and extension at $72^{\circ} \mathrm{C}$ for $40 \mathrm{~s}$, with a final extension performed at $72^{\circ} \mathrm{C}$ for five minutes.

The PCR products were visualized on a $1.0 \%$ agarose gel (Promega) stained with ethidium bromide. Visualization was performed using ChemiDoc, MP Lab software (Imagine, Bio-Rad). The PCR amplicons were purified using a PCR Clean-Up Kit (Genoplast). The purified PCR products were sequenced in both directions by Genomed (Poland) and assembled into contigs using ContigExpress, Vector NTI Advance 11.0 (Invitrogen Life Technologies, USA). The derived sequences were submitted to GenBank/ EMBL.

All isolated metacestodes have been identified as cysticerci of T. hydatigena on the basis of size and shape of rostellar hooks and molecular analysis of the partial sequences of cytochrome $\mathrm{c}$ oxidase subunit 1 gene.

Cysticerci were oval in shape, opalescent white, with invaginated scolex. Diameter of the metacestodes ranged

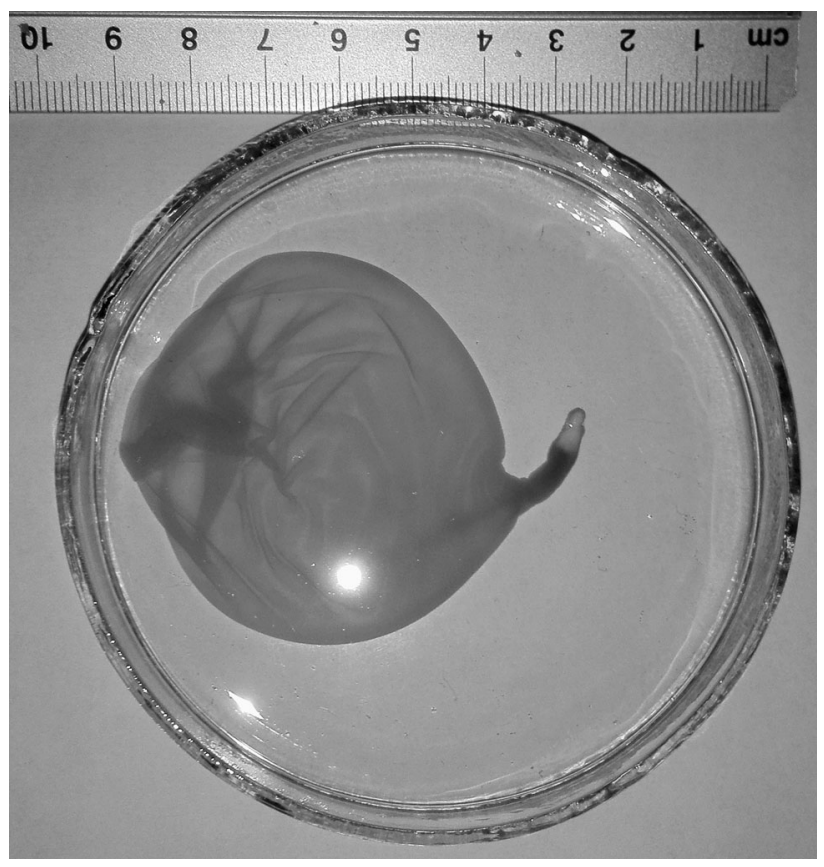

Figure 1. Metacestode of Taenia hydatigena from the mediastinum of moose (Alces alces). 

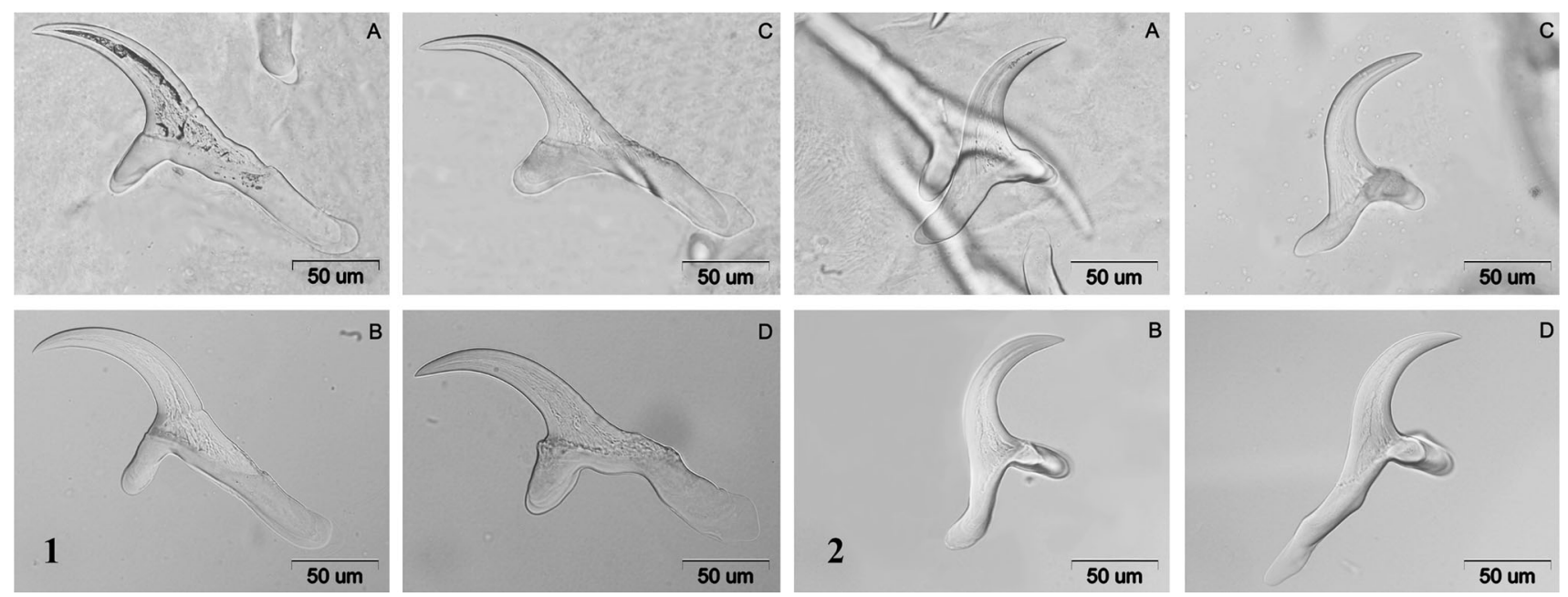

Figure 2. Large (1) and small (2) rostellar hooks of Taenia hydatigena metacestode from the liver of wild boars (A, B), liver of moose (C) and mediastinum of moose (D).

Table 1. Measurements of Large and Small Hooks of Polish Isolates of Taenia hydatigena Found in the Liver of Two Wild Boars and One Moose (Larva no. 1 Isolated from the Liver; Larva no. 2 Isolated from the Mediastinum).

\begin{tabular}{|c|c|c|c|c|c|c|c|c|c|c|c|c|}
\hline \multirow[t]{3}{*}{ Feature } & \multicolumn{6}{|c|}{ Sus scrofa } & \multicolumn{6}{|c|}{ Alces alces } \\
\hline & \multicolumn{3}{|c|}{ Individual no.1 } & \multicolumn{3}{|c|}{ Individual no. 2} & \multicolumn{3}{|c|}{ Larva no. 1} & \multicolumn{3}{|c|}{ Larva no. 2} \\
\hline & $n$ & Mean & Range & $n$ & Mean & Range & $n$ & Mean & Range & $n$ & Mean & Range \\
\hline \multicolumn{13}{|l|}{ Large hooks } \\
\hline Total length (TL) & 6 & 221.3 & 219.4-223.7 & 10 & 204.9 & $202.7-206.9$ & 6 & 225.7 & $223.5-227.4$ & 7 & 222.5 & $218.0-226.0$ \\
\hline Total width (TW) & 6 & 74.6 & $72.6-75.7$ & 10 & 82.6 & $80.6-84.4$ & 6 & 81.5 & $79.8-83.7$ & 7 & 78.0 & $72.4-80.8$ \\
\hline Basal length (BL) & 6 & 136.3 & $132.0-139.4$ & 10 & 123.2 & $119.3-128.8$ & 6 & 146.5 & $144.6-148.7$ & 7 & 136.1 & $131.4-142.0$ \\
\hline Apical length (AL) & 6 & 103.1 & $100.4-108.6$ & 10 & 98.7 & $97.3-100.7$ & 6 & 106.2 & $103.9-107.8$ & 7 & 103.4 & $99.5-106.5$ \\
\hline Guard length (GL) & 6 & 36.4 & $31.9-39.0$ & 10 & 34.0 & $32.6-36.9$ & 6 & 35.1 & $33.6-36.7$ & 7 & 34.6 & $31.7-37.9$ \\
\hline Guard width (GW) & 6 & 28.6 & $24.4-36.9$ & 10 & 19.2 & $17.5-20.9$ & 6 & 21.2 & $20.5-22.3$ & 7 & 27.5 & $24.5-29.3$ \\
\hline Blade curvature (BC) & 6 & 19.3 & $18.3-21.3$ & 10 & 25.5 & $24.8-26.5$ & 6 & 18.5 & $17.0-19.2$ & 7 & 19.8 & $17.8-22.3$ \\
\hline Handle width (HW) & 6 & 28.4 & $24.0-32.8$ & 10 & 23.3 & $20.9-26.8$ & 6 & 22.5 & $21.2-24.1$ & 7 & 26.1 & $24.2-29.7$ \\
\hline \multicolumn{13}{|l|}{ Small hooks } \\
\hline Total length (TL) & 5 & 131.8 & $126.8-136.6$ & 11 & 133.6 & $131.1-136.3$ & 6 & 146.8 & $142.2-149.7$ & 5 & 171.1 & $166.3-176$ \\
\hline Total width (TW) & 5 & 74.3 & $69.7-76.5$ & 11 & 71.8 & $68.6-79.1$ & 6 & 72.2 & $70.2-74.1$ & 5 & 74.5 & $72.6-77.5$ \\
\hline Basal length (BL) & 5 & 77.7 & $75.1-80.0$ & 11 & 79.2 & $77.3-84.2$ & 6 & 90.2 & $87.0-91.9$ & 5 & 114.4 & $107.4-123.4$ \\
\hline Apical length (AL) & 5 & 85.2 & $80.0-89.3$ & 11 & 74.4 & $70.4-79.4$ & 6 & 82.0 & $79.9-84.2$ & 5 & 80.1 & $75.4-83.5$ \\
\hline Guard length (GL) & 5 & 30.7 & $25.3-37.3$ & 11 & 30.8 & $25.7-37.6$ & 6 & 26.1 & $24.5-28.3$ & 5 & 33.9 & $30.3-37.3$ \\
\hline Guard width (GW) & 5 & 18.6 & $17.0-20.3$ & 11 & 15.9 & $15.3-18.4$ & 6 & 22.1 & $20.6-23.4$ & 5 & 17.7 & $17.4-18.1$ \\
\hline Blade curvature (BC) & 5 & 22.1 & $20.2-23.6$ & 11 & 23.1 & $21.9-23.7$ & 6 & 19.6 & $18.1-21.8$ & 5 & 18.6 & $16.9-20$ \\
\hline Handle width (HW) & 5 & 15.6 & $14.4-17.2$ & 11 & 15.3 & $14.5-16.3$ & 6 & 18.5 & $17.9-18.9$ & 5 & 16.9 & $15.7-18.4$ \\
\hline
\end{tabular}

from $1.5 \mathrm{~cm}$ (cysticerci from the liver of wild boars and moose) to $5 \mathrm{~cm}$ (cysticerci from the moose mediastinum) (Fig. 1).

The rostellum of $T$. hydatigena metacestodes from wild boars was armed with 32 small and large hooks, while those obtained from the liver and mediastinum in moose had 34 and 30 hooks, respectively (Fig. 2). The measurements of small and large hooks are included in Table 1.

Four nucleotide sequences of the coxl region of the isolated metacestodes were obtained during the study 


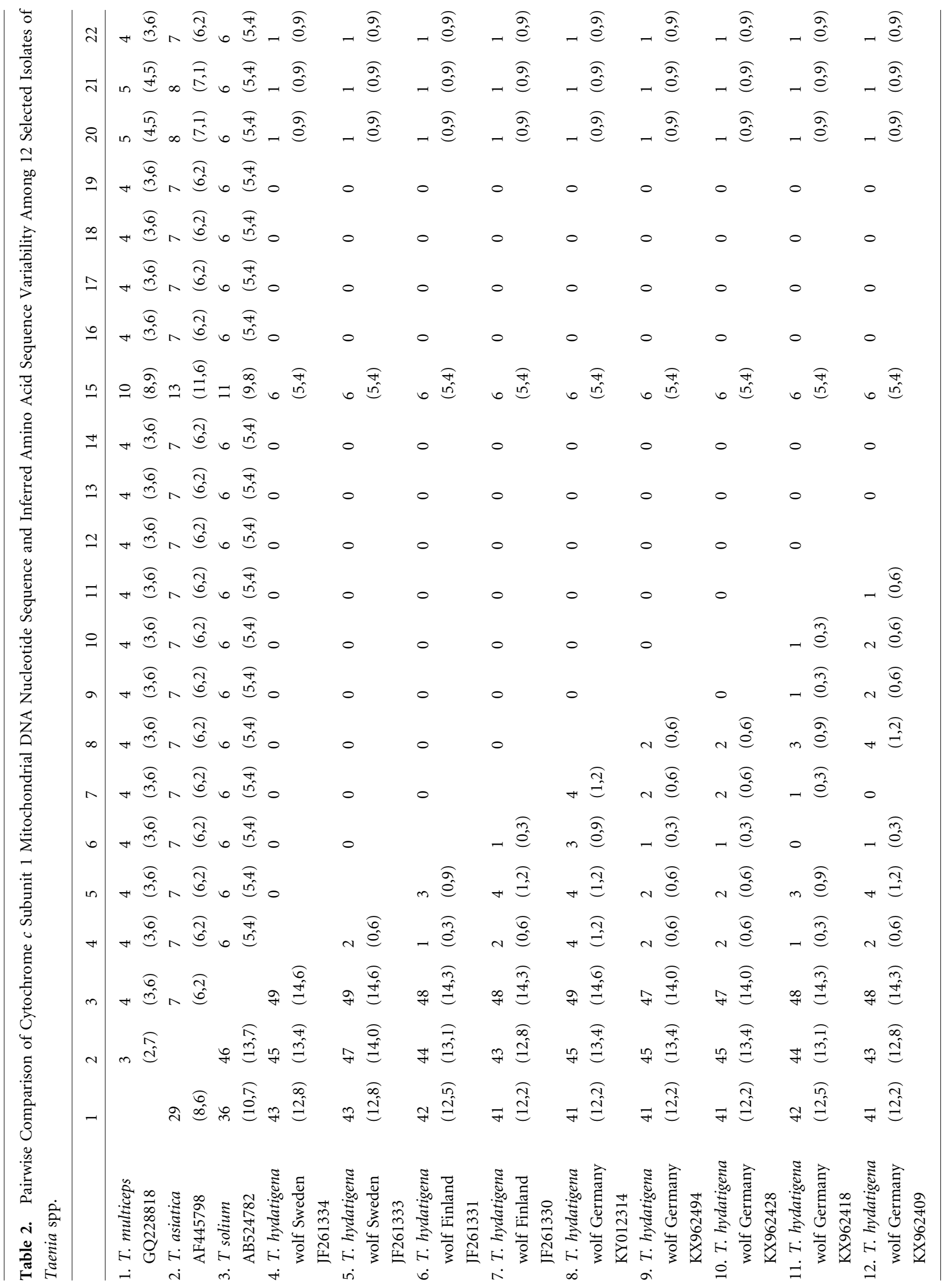




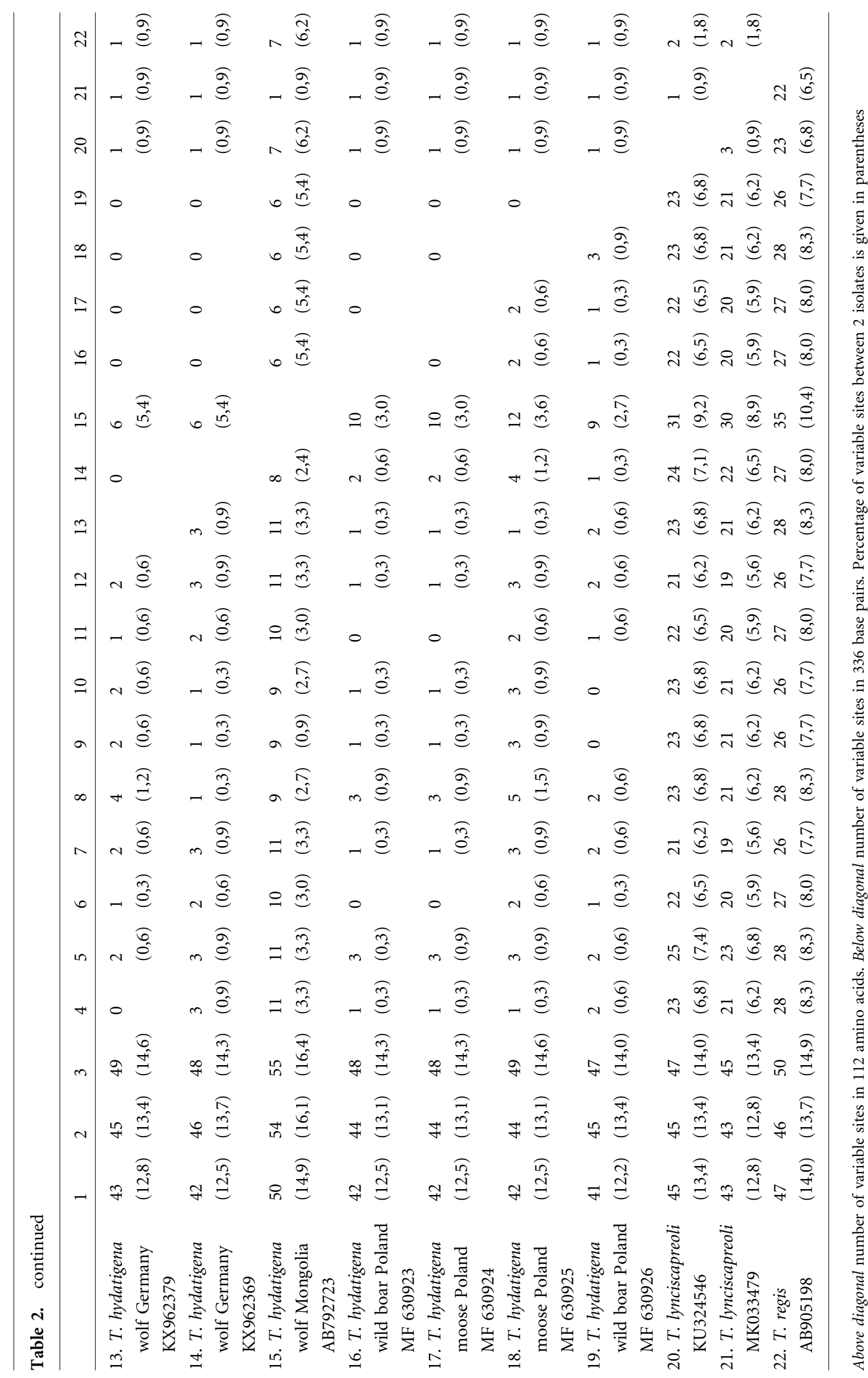




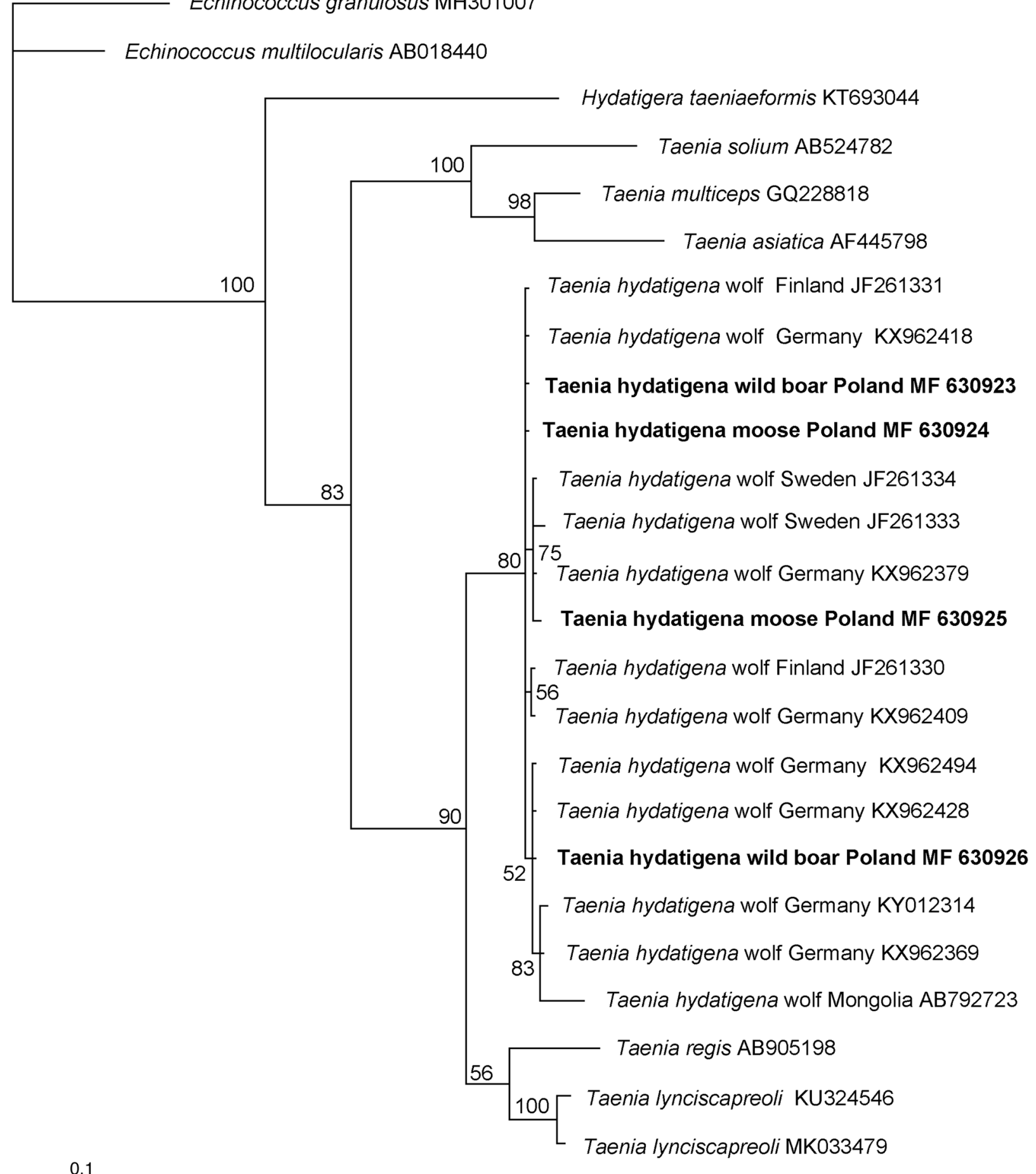

Figure 3. Phylogenetic tree of Taenia hydatigena haplotypes, constructed by Bayesian inference (BI) analysis using MrBayes version 3.2. For BI codon analysis (nucmodel = codon), the HKY + I + G model was chosen based on jModelTest version 2.1.4 (Guindon and Gascuel 2003; Darriba et al. 2012) using Akaike information criterion. Analysis was run for 3,000,000 generations, with 750,000 generations discarded as 'burn-in'. Hosts, country and GenBank accession numbers of origin are shown (host and country are given only for T. hydatigena haplotypes). Nodal support is indicated as Bayesian posterior probabilities. Sequences from Echinococcus granulosus (MH301007), E. multilocularis (AB018440) and Hydatigera taeniaeformis (KT693044) were used as outgroup. Sequences generated in this study are shown in bold. The scale bars are proportional to the number of substitutions per site. 
(GenBank accession nos.: MF630923, MF630924, MF630925, MF630926). The length of each obtained sequence was $735 \mathrm{bp}$.

Analysis performed in the BLAST sequence analysis tool revealed the similarity of obtained sequences to a number of metacestodes of $T$. hydatigena from southern Europe and Asia. Isolates from the liver of first wild boar and moose (GenBank accession nos: MF630923, MF630924) were identical to those obtained from sheep in Sardinia, Italy (GenBank accession nos: KT372528, KT372525, KT372524), Iran (GenBank accession no: JQ710593) and India (GenBank accession no: DQ995656). Metacestode from the liver of second wild boar could be compared to sequences of T. hydatigena from sheep in Italy (GenBank accession nos: KT372530, KT372529, KT372522) and Iran (GenBank accession no: JQ710588) as well as goats in Iraq (GenBank accession no: MN638348) and China (GenBank accession nos: KT258027, JN831298, JN831297, JN831295, JN831294, JN831291). Only the sequence of $T$. hydatigena metacestode from moose mediastinum had no matches in the BLAST analysis.

For more informative comparison, relevant sequences of T. hydatigena and other Taeniidae species were downloaded from the GenBank database and used in the Bayesian analysis (Table 1 in Appendix 1 in ESM).

Bayesian analysis of cox 1 sequences (Fig. 3) revealed that $T$. hydatigena from the liver of wild boar and moose (intermediate hosts) from Poland (GenBank accession nos.: MF630923, MF630924) are included in the subclade together with $T$. hydatigena from wolves (definitive host) in Germany (GenBank accession no: KX962418) and Finland (GenBank accession no: JF261331). Taenia hydatigena from the liver of second wild boar (GenBank accession no: MF630926) is included together with $T$. hydatigena from wolves in Germany (GenBank accession nos: KX962428, KX962494) whereas isolate of $T$. hydatigena from moose mediastinum (GenBank accession no. MF630925) is included in the subclade together with isolates from wolves in Sweden (GenBank accession nos. JF261333, JF261334) and Germany (GenBank accession no. KX962379).

Comparisons of both the nucleotide and amino acid sequences derived from the cox 1 gene of the analyzed species of Taenia are presented in Table 2.

Nucleotide sequences of T. hydatigena from moose and wild boars diverged significantly from T. multiceps (GenBank accession no:GQ228818), T. asiatica (GenBank accession no:AF445798) and T. solium (GenBank accession no:AB524782) and ranged between 12.2 and $14.6 \%$. Nu- cleotide sequence variation in the coxl gene between metacestodes of $T$. hydatigena and isolates of $T$. lynciscapreoli (GenBank accession nos: KU324546) and T. regis (GenBank accession no:AB905198) was also significant (5.9-8.3\%), whereas it reached only $0.9 \%$ at the amino acid level. The metacestodes isolated from the liver of wild boars and moose were identical at the amino acid level to those taken from wolves in Sweden (GenBank accession nos: JF261334, JF261333), Finland (GenBank accession nos:JF261331, JF261330) and Germany (GenBank accession nos.: KY012314, KX962494,KX962428, KX962418, KX962409, KX962379, KX962369), whereas their nucleotide sequences diverged slightly $(0.30-1.5 \%)$.

In addition, greater divergence was found between the coxl gene sequences present in our isolates and that obtained from Mongolian isolates (GenBank accession no. AB792723), ranging from 2.7 to $3.6 \%$. Furthermore, European isolates of $T$. hydatigena, including those of the present study, and an isolate from a wolf from Mongolia also demonstrated significant differences at the amino acid level $(5.4 \%)$.

Molecular and morphological identification confirmed the occurrence of T. hydatigena in the tested samples.

According to previous data, there is strong intraspecific variability of hook measures in T. hydatigena (Haukisalmi et al. 2011), which is confirmed in our study. There are several reports concerning measurements of $T$. hydatigena adult and metacestode stages (Verster 1969; Loos-Frank 2000; Gomez-Puerta et al. 2015; Singh et al. 2015). Size and shape of our metacestodes are consistent with the data given by Verster (1969) and Loos-Frank (2000). Large hooks of our metacestodes had higher total length than metacestodes from domestic ruminants in India with overlapping total length of small hooks (Singh et al. 2015), whereas large and small hooks of metacestodes from wild ruminants in Peru were smaller than ours (Gomez-Puerta et al. 2015). It might be a result of the effect of different intermediate host on rostellar hooks of metacestodes as well as environmental and genetic components (Lymbery 1998). In our studies, total and basal lengths of small hooks were higher in metacestodes from moose than from wild boars, which might be also a reflection of the intermediate host effect.

Although the intraspecific variability of T. hydatigena is considered to be high (Kędra et al. 2001), differences between our sequences of $T$. hydatigena metacestodes and $T$. hydatigena from European wolves were small and ranged from $0.30 \%$ to $1.5 \%$ (Table 2 ). The differences identified in 
nucleotide sequence between the European isolates of $T$. hydatigena were of the order of individual bases and did not affect their amino acid structure. In contrast, the amino acid sequence of $T$. hydatigena from Mongolia differed significantly from European isolates, which can be attributed to the geographical distribution of the tapeworm.

The genetic identity between the isolates from moose and wild boar analyzed in the present study and those taken from wolves from Western Europe indicate that wolves are definitive hosts of T. hydatigena. Recent studies have revealed that ungulates sharing the same territory with wolves tend to demonstrate a significantly higher prevalence of metacestode infection than ruminants inhabiting other areas (Lesniak et al. 2017). Therefore, infection of moose and wild boar in Poland with T. hydatigena may result from growing levels of wolf colonization across the country (Nowak and Mysłajek 2016). Recent studies indicate that the wolf population has increased from 500 to over 1500 individuals over the last decade (Diserens et al. 2017). The genetic similarity of our metacestodes to T. hydatigena from wolves across the German border may be accounted for by the fact that the wolves inhabiting north-eastern Poland migrated and settled in western Poland and Germany, forming a Central European wolf population (Czarnomska et al. 2013).

The rapid increase in the moose and wild boar populations in Poland (Filip and Demiaszkiewicz 2016; Flis 2011), together with the growing numbers of wolves, allow the life cycle of $T$. hydatigena to be easily closed. Although moose and wild boar are typical intermediate hosts of $T$. hydatigena, the parasite has not been commonly observed in wild mammals in Poland (Gadomska 1981; Tropiło and Kiszczak 1995). All previous studies in Poland referred to larvae of T. hydatigena located typically, in the abdominal cavity, and so it was in three out of four metacestodes isolated during this study. However, one of metacestodes from moose was found in the mediastinum. Radfar et al. (2005) observed T. hydatigena metacestodes in the thoracic cavity only in $1.24 \%$ of examined animals while most of data refer to larvae of $T$. hydatigena in the abdomen cavity (Järvis et al. 2007; Gomez-Puerta et al. 2015; Scala et al. 2015; Singh et al. 2015). The metacestode from moose mediastinum differs from other isolates not only by location in the host but also by different haplotype with no matches in the BLAST analysis. Detection of two different isolates of $T$. hydatigena metacestode in a single moose indicates two irrespective sources of the infection and can be evidence of a high level of contamination of the environment with invasive forms of the cestode. It might be a threat not only for domestic animals but also for farmed cervids, which are especially exposed to contact with both wild and domestic carnivores.

Although wolves, as definitive hosts of T. hydatigena, are considered as playing a marginal role in the spread of the cestode to domestic dogs, it is possible that hunting dogs fed with offal from ungulates or stray dogs fed with carrion may remain at serious risk of infection (Otranto et al. 2015). According to Lahmar et al. (2017), in some countries rural stray dogs are mainly transmitting the tapeworm in the environment. Taenia hydatigena was also detected in dogs in Poland and Ukraine (Okulewicz et al. 1994; Komyushin et al. 2013; Karamon et al. 2016). All infected animals came from rural areas, which can be evidence that dogs, on contact with wild animals and carrion, should be considered as an important source of T. hydatigena infection in this part of Europe. Also jakals, which have begun to expand in Poland recently may play a role in spreading $T$. hydatigena infection (Kowalczyk et al. 2015). Therefore, it is essential to begin regular monitoring of T. hydatigena infection in both wild and domestic animals in Poland and to determine which canids are involved in spreading the cestode in the wild.

The detection of T. hydatigena in wild mammals from eastern and central Poland and its similarity to T. hydatigena identified in wolves in Germany indicates that the recolonization of Western Europe by wild carnivores should be considered successful. However, the relationships between parasites, wild and domestic hosts, the size of the host population and its geographical distribution should be taken into account when estimating the risk of infection with parasitic diseases. Further studies are required to determine the prevalence of T. hydatigena in wild herbivores, omnivores and carnivores in Poland and to fully evaluate the risk of infection in domestic animals.

\section{ACKNOWLEDGEMENTS}

The authors would like to thank the management and staff of the Strzałowo Forest District and Kampinos National Park, especially Adrian Biedka, for assistance in animal necropsies and material collection. This study is a part of a $\mathrm{PhD}$ thesis concerning endoparasites of moose in Poland.

\section{Compliance with Ethical Standards}

CONFLICT OF INTEREST The authors declare that they have no conflict of interest. 


\section{Statement of Human and Animal} RIGHTS This article does not contain any studies with human participants or animals performed by any of the authors.

\section{Open Access}

This article is distributed under the terms of the Creative Commons Attribution 4.0 International License (http://c reativecommons.org/licenses/by/4.0/), which permits unrestricted use, distribution, and reproduction in any medium, provided you give appropriate credit to the original author(s) and the source, provide a link to the Creative Commons license, and indicate if changes were made.

\section{REFERENCES}

Bowman DD (2009) Georgis' Parasitology for Veterinarians, 9th $e d$., St Louis: Saunders

Czarnomska SD, Jędrzejewska B, Borowik T, Niedziałkowska M, Stronen AV, Nowak S, et al. (2013) Concordant mitochondrial and microsatellite DNA structuring between Polish lowland and Carpathian Mountain wolves. Conservation Genetics 14:573588. https://doi.org/10.1007/s10592-013-0446-2

Darriba D, Taboada GL, Doallo R, Posada D (2012) jModelTest 2: more models, new heuristics and parallel computing. Nature Methods 9:77. https://doi.org/10.1038/nmeth.2109

Diserens TA, Borowik T, Nowak S, Szewczyk M, Niedźwiecka N, Mysłajek RW (2017) Deficiencies in Natura 2000 for protecting recovering large carnivores: A spotlight on the wolf Canis lupus in Poland. PLoS ONE 12:1-20. https://doi.org/10.1371/journal.pone.0184144

Dróżdż J (1966) Studies on helminths and helminthiases in Cervidae II. The helminth fauna in Cervidae in Poland. Acta Parasitologica Polonica 14:1-13

Filip KJ, Demiaszkiewicz AW (2016) Internal parasitic fauna of elk (Alces alces) in Poland. Acta Parasitologica 61:657-664. https:// doi.org/10.1515/ap-2016-0092

Flis M (2011) Wild boar population management versus damage conditions in economical and social grasps. Annals of Warsaw University of Life Sciences-SGGW. Animal Science 50:43-50

Gadomska K (1981) The qualitative and quantitative structure of the helminthocoenosis of wild boar (Sus scrofa L.) living in natural (Kampinos National Park) and breeding conditions. Acta Parasitologica Polonica 28:151-170

Gomez-Puerta L, Pacheco J, Gonzales-Viera O, Gonzalez AE (2015) The taruca (Hippocamelus antisensis) and the red brocket deer (Mazama americana) as intermediate hosts of Taenia hydatigena in Peru, morphological and molecular evidence. Veterinary Parasitology 212:465-468. https://doi.org/10.1016/ j.vetpar.2015.08.004

Gori F, Armua-Fernandez MT, Milanesi P, Serafini M, Magi M, Deplazes P, et al. (2015) The occurrence of taeniids of wolves in
Liguria (northern Italy). International Journal for Parasitology: Parasites and Wildlife 4:252-255. https://doi.org/10.1016/j.ijppaw.2015.04.005

Guindon S, Gascuel OA (2003) Simple, fast, and accurate algorithm to estimate large phylogenies by maximum likelihood. Systematic Biology 52:696-704

Haukisalmi V, Lavikainen A, Laaksonen S, Meri S (2011) Taenia $\operatorname{arctos}$ n. sp. (Cestoda: Cyclophyllidea: Taeniidae) from its definitive (brown bear Ursus arctos Linnaeus) and intermediate (moose/elk Alces spp) hosts. Systematic Parasitology 80:217-230. https://doi.org/10.1007/s11230-011-9324-9

Järvis T, Kapel Ch, Moks E, Talvik H, Magi E (2007) Helminths of wild boar in the isolated population close to the northern border of its habitat area. Veterinary Parasitology 150:366-369. https://doi.org/10.1016/j.vetpar.2007.09.015

Karamon J, Samorek-Pierog M, Kochanowski M, Dabrowska J, Sroka J, Golab E, Umhang G, Cencek T (2016) First detection of Echinococcus multilocularis in dogs in a highly endemic area of Poland. Folia Parasitologica. https://doi.org/10.14411/fp.2016. 018

Kędra AH, Tkach VV, Świderski Z, Pawłowski Z (2001) Intraspecific variability among NADH dehydrogenase subunit 1 sequences of Taenia hydatigena. Parasitology International 50:145-148. https://doi.org/10.1016/s1383-5769(01)00064-2

Kornyushin VV, Malyshko EI, Malega OM (2013) Domestic dogs and cats as the reservoir of natural nidi and zoonotic helminthoses under present conditions in Ukraine. Veterinarna Medicina 97:383-387(in Ukrainian)

Kowalczyk R, Kołodziej-Sobocińska M, Ruczyńska I, Wójcik JM (2015) Range expansion of the golden jackal (Canis aureus) into Poland: first records. Mammal Research 60:411-414. https:// doi.org/10.1007/s13364-015-0238-9

Lahmar S, Arfa I, Othmen SB, Jguirim W, Saïd Y, Dhibi A, et al. (2017) Intestinal helminths of stray dogs from Tunisia with special reference to zoonotic infections. Parasitology Open. https://doi.org/10.1017/pao.2017.21

Lesniak I, Heckmann I, Heitlinger E, Szentiks CA, Nowak C, Harms V, et al. (2017) Population expansion and individual age affect endoparasite richness and diversity in a recolonising large carnivore population. Scientific Reports 7:41730. https://doi.org/ 10.1038/srep41730

Letkova V, Lazar P, Soroka J, Goldova M, Urlik J (2008) Epizootiology of game cervid cysticercosis. Natura Croatica 17:311318

Loose-Frank B (2000) An up-date of Verster's (1969) 'Taxonomic revision of the genus Taenia Linnaeus' (Cestoda) in table format. Systematic Parasitology 45:155-184. https://doi.org/ 10.1023/a:1006219625792

Lymbery AJ (1998) Combining data from morphological traits and genetic markers to determine transmission cycles in the tape worm, Echinococcus granulosus. Parasitology 117:185-192

Nguyen MT, Gabriël S, Abatih EN, Dorny P (2016) A systematic review on the global occurrence of Taenia hydatigena in pigs and cattle. Veterinary Parasitology 226:97-103. https://doi.org/ 10.1016/j.vetpar.2016.06.034

Nowak S, Mysłajek R (2016) Wolf recovery and population dynamics in Western Poland, 2001-2012. Mammal Research 61:83-98. https://doi.org/10.1007/s13364-016-0263-3

Okulewicz A, Złotorzycka J, Czułowska A (1994) Effect of environmental conditions on parasitic infection of dogs. Wiadomości Parazytologiczne 40:293-298 
Otranto D, Cantacessi C, Dantas-Torres F, Brianti E, Pfeffer M, Genchi C, et al. (2015) The role of wild canids and felids in spreading parasites to dogs and cats in Europe. Part II: Helminths and arthropods. Veterinary Parasitology 213:24-37. https://doi.org/10.1016/j.vetpar.2015.04.020

Radfar MH, Tajalli S, Jalalzadeh M (2005) Prevalence and morphological characterization of Cysticercus tenuicollis (Taenia hydatigena cysticerci) from sheep and goats in Iran. Veterinarski Arhiv 75:469-476

Rostami S, Salavati R, Beech RN, Babaei Z, Sharbatkhori M, Baneshi MR, et al. (2013) Molecular and morphological characterization of the tapeworm Taenia hydatigena (Pallas, 1766) in sheep from Iran. Journal of Helminthology 89:1-8. https:// doi.org/10.1017/s0022149x13000667

Scala A, Pipia AP, Dore F, Sanna G, Tamponi C, Marrosu R, et al. (2015) Epidemiological updates and economic losses due to Taenia hydatigena in sheep from Sardinia, Italy. Parasitology
Research 114:3137-3143. https://doi.org/10.1007/s00436-0154532-x

Shimalov VV, Shimalov VT (2003) Helminth fauna of cervids in Belorussian Polesie. Parasitology Research 89:75-76. https:// doi.org/10.1007/s00436-002-0700-x

Singh BB, Sharma R, Gill JPS, Sharma JK (2015) Prevalence and morphological characterisation of Cysticercus tenuicollis (Taenia hydatigena cysts) in sheep and goat from north India. Journal of Parasitic Diseases 39:80-84. https://doi.org/10.1007/ s12639-013-0284-7

Tropiło J, Kiszczak L (1995) Cysticercosis in roe deer caused by Cysticercus tennuicollis and C. cervi. Magazyn Weterynaryjny $4: 433$

Verster A (1969) A taxonomic revision of the genus Taenia Linnaeus, 1758, s. str. Onderstepoort Journal of Veterinary Research $36: 3-58$ 